\title{
La formación del homo pedagogicus: entre la lectura y la escritura
}
Revista Colombiana
Reflexiones de Educación, N. ${ }^{\circ} 67$. Segundo semestre de 2014 Bogotá, Colombia.

\section{//Homo Pedagogicus Training: \\ Between Reading and Writing}

//A formação do homo pedagogicus:

entre a leitura e a escritura

Nylza Offir García Vera*

Recibido: 28/08/2014 Evaluado: $16 / 11 / 2014$ $13 / 11 / 2014$ $22 / 11 / 2014$

\begin{abstract}
Profesora de la Universidad Pedagógica Nacional. Licenciada en Pedagogía; Especialista en Enseñanza del Español y la Literatura y Magíster en Educación. Fue editora de la revista Pedagogía y Saberes durante 2009 y 2012 y actualmente se desempeña en docencia e investigación en las áreas de Lectura y Escritura para la educación básica y la educación superior; Pedagogías del lenguaje y la literatura; y vínculos entre formación docente, cultura académica y prácticas lectoras y escriturales. nylzao@yahoo.es.
\end{abstract}

\section{Resumen}

El artículo, basado en algunos hallazgos de la investigación interuniversitaria: ¿Para qué se lee y se escribe en la universidad colombiana?, sitúa la reflexión en torno a la formación inicial de maestros en lectura y escritura. En ese sentido, vuelve la mirada sobre la formación humanística y pedagógica cada vez más ausente de las licenciaturas o carreras en educación. Asimismo, propone que leer y escribir son prácticas fundantes y constitutivas de la profesión docente, y por lo tanto, el vínculo con la cultura escrita es central en la formación del homo pedagogicus, en tanto maestro-lector.

\section{Abstract}

This article, based upon some findings of the inter-university research entitled What's the Purpose of Reading and Writing at University Level in Colombia?, places the reflection on initial teacher training in reading and writing. It looks back on the humanistic and pedagogical training, increasingly absent from bachelor's courses in education. It also proposes that reading and writing are foundational and constitutive practices of teaching and, therefore, the connection with written culture is crucial in the training of Homo pedagogicus, in his or her role as a teacher-reader.

\section{Resumo}

O artigo, baseado em alguns resultados da pesquisa interuniversitária: Para que se lê e se escreve na universidade colombiana?, Situa a reflexão em volta à formação inicial de educadores em leitura e escritura. Neste sentido, volta à perspectiva sobre a formação humanística e pedagógica cada vez mais ausente das licenciaturas ou cursos em educação. Mesmo assim, propor que ler e escrever são práticas fundacionais e constitutivas da profissão docente e, portanto, o vínculo com a cultura escrita é central na formação do homo pedagogicus, entanto mestre-leitor.

\section{Palabras clave}

Formación inicial docente, lectura, escritura, homo pedagogicus.

\section{Keywords}

Initial teacher training, reading, writing, Homo pedagogicus.

\section{Palavras chave}

Formação inicial docente, leitura, escritura, homo pedagogicus. 


\section{Puntos de partida o contexto de la reflexión}

Entre los años 2009 y 2012, un grupo de profesores provenientes de 17 universidades del país nos reunimos para pensar y desarrollar como problema de investigación la pregunta por el tipo de prácticas de lectura y escritura que circulaban en la universidad colombiana. Ello, en la perspectiva de indagar por la idea de cultura académica instituida en la universidad, y, en consecuencia, por los modos de leer y escribir de los estudiantes universitarios (futuros profesionales). Tales modos fueron considerados, en parte, como un efecto de las prácticas pedagógicas y didácticas de los docentes.

Nos animó el propósito de describir, caracterizar, analizar e interpretar esas prácticas porque intuíamos que estas no tenían un modo estable de ser, que se configuraban según el tipo de profesiones y comunidades disciplinares en las que se estaban incorporando los estudiantes, y que, además, se actualizaban o modificaban de acuerdo con los requerimientos de cada docente como mecanismos de supervivencia académica. Para cumplir este objetivo, se recolectó y analizó información documental (políticas de lectura y escritura de cada universidad y programas de cursos o syllabi relacionados con la lengua); se caracterizó la voz de los estudiantes por medio de una encuesta y unos grupos de discusión (que también se desarrollaron con profesores); y se realizaron estudios de caso de prácticas docentes identificadas como "destacadas", en cuanto fueron consideradas por los estudiantes como experiencias formativas importantes mediadas por la lectura y la escritura con significado para ellos.

De todo este cúmulo de información, ya están publicados los más importantes hallazgos (Pérez, A. y Rincón G., 2013), y también circulan diferentes artículos que se enfocan en una fuente de información o en varias, en una de las técnicas, o en un hallazgo en particular ${ }^{1}$. Para la presente reflexión nos interesa poner de relieve algunos de estos hallazgos en el área de educación, en contraste con otras carreras y profesiones ${ }^{2}$. Esto en la perspectiva

1 Tarea que iniciamos al presentar los resultados específicamente en la formación universitaria de docentes, y, en particular, situando los hallazgos en el contexto de la Universidad Pedagógica Nacional, única universidad en Colombia que se dedica en exclusivo a la formación docente (ver García-Vera, 2011).

2 De acuerdo con la clasificación de las áreas según Unesco: Humanidades y Artes; Ciencias sociales, Educación comercial y Derecho; Ciencias; Ingenierías, Industria y Construcción; Agricultura; Salud y Servicios Sociales; y Servicios. 
de articularlos con la tesis de que la lectura y la escritura son prácticas fundantes y constitutivas de la profesión de maestro y, por ello, requieren ser asumidas más allá de cursos iniciales de lengua, en el marco de un proceso formativo estructural a los currículos de licenciatura. Aquí se requiere el diálogo entre profesores de lengua y profesores de asignaturas propiamente disciplinares o esenciales a la profesión. Pero también es necesario que en esos diferentes espacios académicos o asignaturas se enseñe y se aprenda a leer y a escribir textos propios de la profesión docente, lo cual implica volver sobre el lugar de la lectura y la configuración del lector mediante la formación pedagógica y humanística de los futuros maestros.

\section{Las prácticas de lectura y escritura en la formación inicial docente: algunas tendencias}

En el marco del estudio al que nos referimos en el acápite anterior se logró identificar algunas tendencias de estas prácticas de lectura y escritura en el área de educación -es decir, en las carreras que se encargan de la formación inicial de maestros en pregrado- por medio de una encuesta dirigida a los estudiantes en las 17 universidades participantes, así como también en los syllabi o programas analíticos de cursos de lengua situados en los ciclos de fundamentación o propedéuticos.
Ahora bien, ¿Qué revelaron estas fuentes de información?

En primer lugar, que la enculturación académica de los futuros docentes tiene más similitudes que diferencias con los demás programas de pregrado. La preferencia por la escritura de textos de naturaleza expositiva y argumentativa tales como los apuntes de clase, el resumen, el ensayo o los informes de lectura es la tendencia general. En cuanto a la lectura, se leen con mayor frecuencia los materiales elaborados por el profesor, los propios apuntes de clase, las páginas web o blogs con contenidos referentes a la carrera, que libros o capítulos de libros. La lectura de artículos científicos es baja en educación en contraste con las áreas de Agricultura y Ciencias. Así también, en la formación docente inicial se escribe más de lo que se leen ciertos textos académicos, tales como el ensayo y la reseña (García-Vera, 2011).

En segundo lugar, a partir de la investigación se precisa que las prácticas de lectura y escritura en educación y en el conjunto general de las carreras tienen un carácter funcional e instrumental, situado en el ámbito de la comprobación o evaluación del nivel de apropiación de los conocimientos específicos de las asignaturas (Pérez y Rincón, 2013). Todo esto es propio de los procesos heteroestructurantes de formación, es decir, es lógico que se lea y se escriba en el marco de una asignatura como respuesta a un requerimiento que viene del profesor -el cual muchas veces se constituye 
en el único destinatario del texto y se acerca al mismo con fines evaluativos-, pero aun así es notoria la ausencia de la lectura y la producción escrita de manera autogestionada por parte de los estudiantes. Por ejemplo, en la perspectiva de la participación en eventos académicos o en grupos de estudio, en donde la motivación particular no está dada por la evaluación o por dar cuenta de lo leído, sino en la construcción de marcos de referencia (teóricos, conceptuales y prácticas) para la interacción con pares, a propósito de eventos convocados en un campo temático o disciplinar.

En tercer lugar, se revela la tendencia sobre el tipo de actividades que se realizan a partir de la lectura de estos documentos indicando que discutirlos oralmente en la clase es lo más frecuente tanto en educación como en el conjunto de las áreas. Le siguen actividades como explorarlos mediante preguntas, así como hacer presentaciones de sus contenidos o exposiciones por parte de los estudiantes. En esta misma línea, hacer comentarios por escrito es más frecuente en el área de educación que en las demás áreas. Finalmente, los hallazgos indican que la lectura de tales documentos se hace preferentemente fuera de clase (García-Vera, 2011; Pérez y Rincón, 2013).

En cuarto lugar, otro dato relevante de la encuesta -que nos sitúa de paso en la siguiente fuente de información correspondiente a los syllabi- es que la asignatura elegida como aquella en la cual leer y escribir se constituyó en una práctica relevante para la formación profesional y académica, se ubica en espacios académicos propios de las carreras y profesiones y no en los cursos de lengua en general. Es decir, la lectura y la escritura en el contexto universitario adquieren relevancia en el marco de los saberes específicos y no en estos cursos anexos o al margen del saber disciplinar o profesional. Valga anotar en todo caso que es positivo, aunque no suficiente, que en el conjunto de las universidades estudiadas se mantenga la idea de cualificar los procesos de lectura y escritura de los estudiantes. De ahí que se ofrezcan cursos de esta naturaleza, prácticamente en todas las carreras.

A propósito de estos cursos de lengua en las carreras de educación, encontramos que son también muy similares a los que se ofrecen en las otras carreras, tanto en sus propósitos como en sus denominaciones ${ }^{3}$. Los syllabi muestran como objetivos

3 Aquí son bastante numerosas y diversas las denominaciones de tales cursos: Expresión Oral y Escrita; Comprensión y Producción de Textos; Lectura y Escritura; Competencias comunicativas, Laboratorio de textos, entre otros. 
explícitos mejorar los procesos de lectura y escritura universitaria, así como comprender los aspectos formales de la lengua y sus características. En educación, tales cursos reportan también como propósito asociado el de "comprender contenidos y textos disciplinares", pero en contraste es exiguo el propósito de "producir textos propios de la profesión" (García-Vera, 2011; Pérez y Rincón, 2013).

Tal panorama se complementa al mirar los tipos de textos que predominan en las demandas de los docentes que desarrollan estos cursos, tanto para la lectura como para la escritura, puesto que allí se priorizan de nuevo los denominados textos académicos (Carlino, 2005). En educación, el mayor porcentaje de escritura lo obtienen los ensayos y en lectura los artículos, valga señalar, sin el adjetivo de científicos. Estos fungen más bien como pretextos para leer y escribir a partir de ellos, pero no se enseña su producción. De acuerdo con esta fuente, no es frecuente la lectura de libros completos, ni novelas o literatura en general, así como tampoco se estimula la producción de reseñas críticas. En síntesis, tales requerimientos de leer y escribir aparecen como entrenamiento para la resolución de actividades propias de las tareas en la universidad, más que de las demandas discursivas del campo profesional y disciplinar.

En este contexto particular, emerge la tensión entre asumir la lectura y la escritura como competencia genérica o como competencia específica propia de la profesión docente. Particularmente, quienes hemos asumido en algún momento la dirección de estos cursos nos encontramos con el cuestionamiento sobre nuestro trabajo, frente a la constante queja de los demás profesores en torno a los "problemas de comprensión" y al precario nivel de escritura reportado por los estudiantes. Aquí, la idea que subyace es similar en la cadena de responsabilidades que se entreteje frente a este problema: se acusa a los profesores de Español en la escuela, estos a su vez a los profesores de básica, quienes sentaron las bases, y así sucesivamente hasta llegar al cuestionamiento sobre las escasas prácticas vinculadas a la cultura escrita en la familia y en el conjunto de la sociedad.

Entonces, ¿quién se hace cargo de esta formación en lectura y escritura? Para Leme Britto (2003), el desarrollo tanto de la conciencia crítica del lenguaje y del discurso, como del dominio de las formas de operación intelectual y social del quehacer académico -en las que el vínculo con la cultura escrita es fundamental y, por tanto, también las prácticas de lectura y escritura que le son propias-, supone una transformación del modelo formativo, lo cual no se logra con la inserción de cursos de redacción en los currículos (p. 90). Para este autor, existen dos cadenas relativamente independientes, aunque complementarias, para la formación intelectual de los sujetos en función de su inserción 
social: la escuela, o la universidad en nuestro caso, y la transmisión cultural constituida por los vínculos socioculturales y por las formas de inserción profesional y política. Esta transmisión implica "frecuentar los lugares en los que se produce la cultura de prestigio, lo que depende de factores tales como el lugar de residencia, el acceso a la información, la disponibilidad de tiempo y de dinero, entre otros" (p. 89).

Siguiendo los razonamientos de la sociología de la reproducción de Bourdieu, Britto señala cómo este último factor, antes que suplirse en las instituciones educativas, repercute negativamente en ellas. Ello explicaría, en parte, dos asuntos que son de conocimiento y debate público con respecto a la formación universitaria de maestros: 1) que los estudiantes de clase sociales más desfavorecidas que ingresan a la carrera docente tengan a su vez bajo rendimiento académico al llegar a la universidad; $y$, 2) que una vez egresados de los programas de formación docente no se logre completamente el vínculo con la cultura escrita. Como este es un asunto del modelo político y económico que no se resuelve al margen de las decisiones en estos campos, la pregunta que queda es ¿qué aportan la escuela o la universidad para paliar tal rezago? Siguiendo las reflexiones del autor:

Desde el punto de vista político-pedagógico, en particular en el ámbito universitario, además de una política pública que combata la educación mercantilista, las acciones que se pueden ejecutar incluyen una perspectiva de formación orientada a la investigación [...] una acción cultural continuada y la reinterpretación del discurso académico, en tanto discurso paradigmático, norma y referencia de valoración del estudiante, lo que acarrea concomitantemente la admisión de otros discursos que el estudiante trae consigo (Leme Britto, 2003, p. 90).

Cabe aclarar el riesgo que supone esto último. Sin embargo, en la lectura global de aquello que propone Leme Britto, no se trata de negar la existencia o especificidad del discurso académico, pues esto es equivalente a negarle al estudiante la posibilidad de adquirirlo e incluso polemizar con él. Se trata más bien de trascender el modelo de transmisión que ha regido para la modalidad de conocimiento que significa aprender a leer y escribir y ser practicante de la cultura escrita. Esto supone una formación que va más allá de la asimilación de una técnica, por una enculturación sostenida mediante una acción pedagógica 
orientada hacia estos dominios. Dominios del lenguaje escrito que implican trabajarlo en sus dimensiones práctica (social y profesional), científica (académica, investigativa y disciplinar) y literaria (estética e imaginativa) (Tolchinsky, 1990), pero también en su especificidad en la formación humanística y pedagógica, para el caso de la formación inicial de maestros. En ello es justamente en lo que nos detendremos en adelante en la presente reflexión.

\section{La formación de maestros en lectura y escritura: ¿"El factor olvidado"?}

La pregunta es nuestra, pero como afirmación de que "el factor olvidado" en la lectura y la escritura es justamente la formación del maestro, se hizo con insistencia hace más de dos décadas (Dubois, 1990). Si acordamos que la lectura y la escritura median nuestra relación con el saber $y$, por tanto, son actividades intelectuales constitutivas de la profesión docente, ello supondría que la formación inicial ha preparado al maestro, al menos, para su desarrollo como lector. Sin embargo, lo que acabamos de revelar en las indagaciones en torno a cómo y qué se lee y se escribe, y qué se desarrolla en los cursos relacionados con la lengua escrita en el marco de las carreras de educación en la universidad, contrasta con la supuesta especificidad de dichas prácticas en la formación de este profesional.
En este escenario, es dable actualizar la consideración que Dubois (1990) hiciera en relación con la necesidad de que el mismo esfuerzo teórico e investigativo, que permitió repensar el quehacer pedagógico para estimular un mejor aprendizaje de los procesos lectoescritores en los niños, es necesario para formar como lectores y escritores a quienes van a desarrollar tales procesos en la escuela. Quizá como ningún otro saber, la lectura y la escritura exigen "el ser para hacer" o "la cualidad de lector y escritor que debe poseer el maestro", precisa la autora (p. 3). Así, "lo que el maestro haga en relación con la lectoescritura, dependerá no solamente de lo que él sepa, sino -y tal vez por encima de cualquier cosa- de lo que él sea" (p. 3$)^{4}$.

Por supuesto, se ha de reconocer que en lo que va de estas afirmaciones de esta autora hasta el presente, aquí en Colombia se han hecho esfuerzos en esa vía, es decir, en cualificar la formación profesional del maestro en tales dimensiones. Pero este esfuerzo ha estado más centrado en la formación continua a través de cursos y programas de actualización en ejercicio. Basta

4 El contexto de tales afirmaciones tenía que ver con los hallazgos de una investigación en la que Dubois estudió las estrategias de lectura de unos grupos de estudiantes de Educación y de Letras (en Buenos Aires y Mérida). Se indagaba allí por medio de las preguntas por hábitos de lectura, problemas de comprensión, autoevaluación y autorregulación de la lectura, entre otros aspectos. La conclusión es contundente: "esos alumnos tenían conocimiento sobre lectoescritura, pero estaban lejos de ser lectores" (p. 4). 
recordar cómo hacia finales de la década del noventa, muchas universidades públicas se hicieron cargo de programas serios y a largo plazo, cuyo énfasis fue el desarrollo pedagógico del lenguaje $y$, en particular, los procesos de lectura y escritura en la escuela. En aquel entonces el Ministerio de Educación (por medio del fondo MEN-Icetex) financió programas que desde las instituciones de educación superior se desarrollaron en varias regiones del país y llegaron a un importante número de maestros. Además, buena parte de esas experiencias formativas se articularon con la Red Nacional para la Transformación de la Formación Docente en Lenguaje, cuyo largo pero sugestivo título da cuenta de esa preocupación central. Dicha red, conformada en 1994, se mantiene vigente hasta hoy en el país y en esta se convocan, mes a mes, y año tras año, grupos de maestros de educación inicial, primaria, secundaria y media vocacional, así como investigadores y profesores universitarios de varias regiones del país para proponer, discutir, investigar, compartir, articular y reinventar las pedagogías de la lectura y la escritura en la escuela ${ }^{5}$.

De manera más reciente, desde 2006, pero vinculada con las corrientes investigativas de "alfabetización académica" y "escritura a través del currículo" (Carlino, 2005), la Red de Lectura y Escritura en la Educación Superior en Colombia, Redlees, promueve la investigación y el desarrollo de experiencias y políticas en este ámbito para todas las carreras y profesiones universitarias. La preocupación allí es también pedagógica, puesto que se intercambian y sistematizan experiencias y se discuten tendencias y enfoques teóricos que subyacen a las propuestas curriculares ${ }^{6}$. Si bien Redlees no se ocupa en particular de la formación profesional docente, la mención es importante puesto que permite poner de relieve cómo el problema de la lectura y la escritura en el país está siendo discutido ampliamente desde diversos espacios de la academia universitaria.

Mientras todo esto ha sucedido durante los últimos veinte años en el campo de la enseñanza de la lectura y la escritura, en ese mismo trayecto la formación profesional docente y la misma

5 Ver en línea Red Colombiana para la Transformación de la formación Docente en Lenguaje [http://www.redlenguaje.com/]

6 En el mes de agosto en la ciudad de Bucaramanga se realizó un evento denominado "Balance y Retos de la Formación en Lectura y Escritura en la Educación Superior 2007 . 2014". En paralelo a esta preocupación en el ámbito nacional, no obstante derivada de las investigaciones y experiencias en la región, existe un proyecto en el que se está elaborando un mapa exhaustivo de la escritura en la educación terciaria (Proyecto llees, en http://www.ilees.org/index.html). 
profesión han tenido que enfrentar un importante número de reformas. Paradójicamente, tales reformas antes que fundamentar y fortalecer la educación y la pedagogía, y situar en el centro de las preocupaciones la apropiación de saberes y prácticas en torno a la lectura y la escritura como piedras angulares de la cultura escolar, han desplazado la discusión hacia la pregunta misma de si es necesario formarse como maestro. En ese camino, la respuesta estatal frente a la necesidad del financiamiento de las instituciones públicas formadoras de maestros -y en especial de la Universidad Pedagógica Nacional- es cada vez más exigua. Parece que el problema de la formación docente tiende a ser más un asunto que le compete de manera individual al sujeto-maestro ${ }^{7}$ y no un problema estructural a un proyecto de Nación, en el cual es notable que la educación sigue estando rezagada. Una sucinta aproximación a lo que ha sucedido en este escenario se desarrolla a continuación.

7 Lo cual se refuerza en el Informe de la Fundación Compartir Tras la excelencia docente (2014), pues si bien ponen en el centro del debate la cualificación del maestro, como base para las transformaciones necesarias en la escuela, no hay allí una sola mención a las instituciones de educación superior que cumplen la tarea de formar a estos profesionales en condiciones cada vez más precarias, debido al desfinanciamiento de la educación superior pública en su conjunto.

\section{La profesión docente y la formación inicial: en un "vaivén sin hamaca"8}

La profesión docente ha transcurrido en estas dos últimas décadas (19942014) en un vaivén sin hamaca, como efecto de las disposiciones de la política al respecto. Verbigracia, desde la Ley General de Educación promulgada en 1994, en la cual se reconocía la profesionalidad del maestro o educador, asistimos hace ya más de una década a un nuevo régimen: profesionales de otros campos y disciplinas han ingresado al sistema educativo bajo el influjo del nuevo estatuto docente (1278/2002), en el que se desplaza la profesión de maestro y aparece la 'función docente'. Para ejercer dicha función, se les exige a estos profesionales solo un requerimiento: tomar un curso de Pedagogía durante un año en una institución de educación superior.

En este escenario, Álvarez y León (2010) se preguntan "¿Para qué formar maestros?". Más aún, interrogan "¿Cómo es posible que en un decreto que habla de profesionalización docente, se establezca que un profesional de la educación puede ser un profesional con título diferente?" (p. 59). La contradicción, afirman, no es solo semántica, sino en esencia, política e histórica. Desde la dimensión histórica, los autores destacan cómo

8 Esta frase en una analogía del libro de Carlos Miñana B. (1999) en torno a la cotidianidad del directivo docente. 
la preocupación por una formación especializada para ejercer la docencia estuvo vigente durante todo el siglo xIx. Asimismo, en la primera mitad del siglo xx, la discusión no fue sobre la especificidad de la formación, dada ya por supuesta, sino que se centró en el tipo de instituciones que debían encargarse de esta tarea. De ahí "la proliferación de las facultades de educación, donde se preparaban los maestros para la educación secundaria, y de escuelas normales donde se siguieron formando los maestros para la primaria" (p. 65). Desde entonces ha habido un importante número de reformas al respecto, pero nunca, sostienen, "se puso en duda que el oficio de maestro era una profesión, y que, por lo tanto, se debían formar en instituciones especializadas en dicho campo" (Álvarez y León, 2010, p. 65).

En cuanto a la dimensión política, además de destacar las lesivas reformas a la profesión ${ }^{9}$, los autores señalan la inconclusión del sistema de formación docente previsto desde la Ley 115 de 1994. En ese marco concluyen: "Estamos contraviniendo la historia, las políticas internacionales y nacionales, y sobre todo, la posibilidad de garantizarles a las nuevas generaciones una escuela capaz de responder a su presente" (p. 68).

Por otra parte, en cuanto la formación profesional docente en su etapa inicial, en algo más de una década se pasó también de la definición de unos "núcleos básicos y comunes del saber pedagógico" a través del Decreto 272 de $1998^{10}$, a una reforma cuyo telón de fondo fueron los nuevos requerimientos para los procesos de acreditación (Decreto 2566 de 2003). En esa misma línea se reformularon las características específicas de los programas en educación a través de la Resolución 1036 de 2004, que en 2010 fueron reformuladas mediante la Resolución 5443. En esta última, el educador es un "profesional con formación pedagógica", que debe responder, para estar más a tono con el lenguaje de las competencias, a un sinnúmero de ellas, dentro de las cuales la primera es la competencia comunicativa. Así, se le exige "comunicarse efectivamente de manera verbal y no verbal. Hablar y escribir de forma coherente de conformidad con las reglas gramaticales y comprender y producir géneros

9 Que se entronizaron mediante un modelo de gestión gerencial y empresarial, la generalización de escuelas Charter, la regulación de los currículos a través de la evaluación de estándares, el discurso de las competencias, entre otros (Álvarez y León, 2010, p. 66).

10 Cuya exigencia fue la aplicación de tales núcleos a los programas curriculares de licenciatura en las facultades de Educación, así como en las escuelas normales, ya reformadas con anterioridad y con decreto propio: 3012 de 1997. 
discursivos inscritos en diversas tipologías textuales" [art. 2].

Aparece entonces aquí el requerimiento explícito de las competencias orales, lectoras y escriturales de los propios profesores ${ }^{11}$. Pero, ¿cómo se incorporó esta dimensión específica en la formación? Por lo menos en los programas curriculares de formación docente, al parecer, tal exigencia ya estaba resolviéndose mediante los cursos de lengua destinados a cualificar la expresión oral o escrita en los ciclos iniciales de estos planes de estudio. Con relación a los profesionales de otras carreras y disciplinas que han ingresado al sistema, al parecer se supondrían tales competencias como adquiridas, pues tampoco hay allí alguna exigencia específica al respecto.

Ahora bien, en este vaivén de la política, de manera más reciente aparecieron los nuevos Lineamientos de calidad para las licenciaturas en Educación (véase la versión preliminar, mayo 5 de 2014). Estos, que quizás muy pronto se legitimarán como nueva política -aunque están en circulación y "discusión" en las comunidades académicas implicadas- simplifican las competencias del maestro a "tres básicas y fundamentales": enseñar, formar y evaluar. Asimismo, al presentar las "condiciones de calidad de los

11 Ya no sabemos si nombrarlos como educadores, maestros, profesionales con formación pedagógica, o como persona que a falta de empleo en su área cumple entonces la función docente en la escuela. programas de pregrado en educación" el documento acoge una perspectiva esbozada por el MEN, en torno a seis temas centrales asociados a las condiciones de calidad, particularmente en lo que se refiere a la apropiación por parte de los estudiantes en su educación superior de:

i) Las gramáticas generales de la academia (en primer lugar la lectura y la escritura, los lenguajes abstractos de la matemática, la lógica y la argumentación, la apropiación crítica y el manejo de la información, el empleo de las tecnologías de la información y la comunicación -TIC-, la capacidad de elaborar representaciones o modelos, el dominio de una segunda lengua) y ii) gramáticas específicas de la disciplina, profesión u oficio [...] (p. 13) ${ }^{12}$.

12 Quienes seguimos el curso de los debates mediáticos sobre la educación en el país, sabemos que estos lineamientos fueron anunciados por el Ministerio de Educación como un "as bajo la manga", en el momento justo en que se producían fuertes cuestionamientos al actual gobierno por cuenta de los pobrísimos resultados de nuestros estudiantes en las pruebas PISA. Especialmente se insiste en el bajo rendimiento en Lenguaje y Matemáticas, y de manera más reciente, en la prueba optativa (Resolución creativa de problemas) en la que de nuevo nuestros estudiantes quedaron rezagados. Sin embargo, el propio Ministerio no se siente interpelado por los efectos que la misma política produce para lograr esta "calidad". Aquí vale la pena retomar las reflexiones que Mauricio Pérez (2013) plantea en su artículo "Estudiantes colombianos 
Como se observa, de la especificidad de la lectura y la escritura como competencias básicas del maestro, se pasa a la generalidad de la gramática de la academia para todas las carreras y profesiones. Por supuesto que no se podría estar en desacuerdo con que se insista en la adquisición de una cultura académica para todos los estudiantes universitarios en el país, más aún si se comprende dicha cultura como la imbricación de cuatro fuentes de conocimiento: la discusión racional; la tradición escrita; el cálculo y el diseño posibilitados por la escritura y otros procedimientos de representación simbólica; y la acción orientada y organizada racionalmente como en el caso de la experimentación científica (Mockus et al. 1997, pp. 63-74). De esta manera, se reconoce también que la lectura y la escritura son prácticas instituidas e instituyentes de esta cultura académica, puesto que no es posible acceder a esa tradición escrita sin el dominio de los códigos que la hacen existir.

No obstante, la enculturación de una gramática académica en la formación inicial del maestro no es un asunto desligado de su gramática específica; más bien esta es constitutiva de la profesión docente, en tanto su actividad simbólica y cultural está vinculada directamente con las prácticas lectoras y escriturales, es más, la caracterizan y diferencian de otras profesiones.

Muchas preguntas quedan hasta aquí, en este apretado recuento del discurso pedagógico oficial. Quizás la primera de ellas es la inocultable ausencia de estudios y evaluaciones de impacto sobre la cultura académica que se promovió en la formación docente, producto de la curricularización de los núcleos del saber pedagógico en las facultades de educación y en las escuelas normales. Sabemos más bien poco de ello, pues su misma indefinición se tradujo en múltiples espacios académicos y asignaturas, que finalmente no constituyeron un núcleo teórico, conceptual, categorial y práctico común a dicha formación, pese al supuesto consenso.

Lo que sí sabemos quienes hemos vivido ese tránsito desde nuestro propio proceso de formación inicial hasta el agenciamiento del mismo ya como formadores de maestros (y a tono con los nuevos decretos y resoluciones), es que tales reformas produjeron la abdicación de algunos proyectos curriculares que contemplaban una formación específica en la educación y, también, una 
amplia formación humanística. Así, muchos planes de estudio de las normales y de las licenciaturas incluían antes el estudio de por lo menos un curso en Filosofía general o en Filosofía de la Educación, en Historia de la Educación e, incluso, en Historia del Arte. También se hallaban importantes cursos de Antropología o Sociología Educativa, así como de Psicología del Desarrollo; todos estos otrora componentes esenciales para prepararse como futuro maestro.

Ahora bien, tales contenidos comportaban una relación específica con la tradición cultural de la educación y con su propia historia. Constituían, como la denomina Ávila (2007), una determinada cultura pedagógica situada en el complejo de discursos teóricos y políticos sobre el ser humano, sobre su existencia y sobre sus condiciones de educabilidad. $Y$ en este marco no resulta comprensible la idea de que cualquier profesional, en unas condiciones de existencia general, pueda ser maestro, o que se trate como ahora de prescribir unas competencias específicas al margen de la discusión central de lo que sería un proceso de enculturación necesario para desarrollarlas. Se trata, como Ávila lo sugiere en una metáfora sociológica a partir de Bourdieu, de volver a plantearnos la pregunta por la formación en una cultura pedagógica para un tipo de ser humano particular, el homo pedagogicus, pues:

Sólo una persona cultivada en y por la cultura pedagógica puede llegar a desarrollar esa actitud del espíritu que permite distinguir a un pedagogo entre mil profesionales: el estilo pedagógico. Algo más que su identidad profesional. Una cierta predisposición para reaccionar a la manera pedagógica. Si el estilo es el hombre [en el sentido general de la especie humana], el estilo pedagógico es el aire de distinción de un pedagogo (Ávila, 2007, p. 21).

Es por eso que tal formación no podría estar desligada de la Historia y Filosofía de la Pedagogía o, por lo menos, de la incidencia de autores clásicos en el ámbito nacional. Ello implica el estudio de la historia de la educación universal y de la historia de la educación en el país, así como la comprensión de la Escuela (como institución social) y las concepciones pedagógicas que le subyacen en diferentes momentos y contextos sociales y culturales, en tanto los sistemas educativos así como las corrientes pedagógicas que les permean son producto y efecto de una historia.

¿De qué otro modo es posible formar maestros comprometidos con el cambio, sin la sensibilidad histórica para identificar las raíces de muchos de nuestros problemas actuales? Es una pregunta que está en el centro de las reflexiones que 
hace el profesor Ávila (2007), entre otros, porque no es posible construir alternativas pedagógicas desde el desconocimiento de la tradición en el campo. De hecho, tanto en las humanidades como en las artes, o en el conocimiento científico y técnico, toda nueva producción es producto de un acumulado en sus propios campos, y no sucede algo distinto con la pedagogía. Así también en ese discurso de las tres competencias (enseñar, formar y evaluar) que sugieren ser el norte hoy para la formación de licenciados no solo se amerita repensar lo que hasta aquí se ha expuesto, sino también comprender que el ser humano está culturalmente dirigido y, por ello, no es únicamente la psicología o las teorías de aprendizaje provenientes de esta disciplina, o las didácticas específicas de cada área (en las que hay desarrollos desiguales), las únicas requeridas para pensar los denominados "ambientes de aprendizaje".

Orientar la educación plena de un ser humano convoca otros conocimientos que otrora eran parte de esa formación pedagógica. Por ello, para formar al homo pedagogicus se requiere un proceso lento y prolongado de enculturación académica, pedagógica y disciplinar, mediado por el estudio, la lectura y la escritura; y esto no se logra con un curso de Pedagogía en unos cuantos meses. La formación de un maestro sucede en el intersticio de un campo pedagógico de naturaleza interdisciplinar, que produce saber para un campo de trabajo social y cultural como lo es la educación (Ávila, 1997).

Así, el maestro -en tanto homo pedagogicus-y su oficio están indefectiblemente vinculados con su capacidad para desplegar una lógica de la reflexión. Lógica que se gana con la apropiación de la cultura escrita, de la práctica del leer y el escribir para el estudio de la Pedagogía y de áreas afines a lo social y a lo humano, además de su relación con un saber disciplinar específico. Es esto, en conjunto, lo que le permite al maestro valorar, analizar, interrogar, proponer y desplegar alternativas de acción pedagógica para la escuela y para la sociedad.

\section{La formación humanística y pedagógica del maestro: entre la lectura y la escritura}

En un texto muy reconocido en el campo de los estudios sobre la lectura, Larrosa advierte que "en la tradición humanística, cuando las letras constituían el núcleo del currículum, la educación era entendida básicamente como lectura. El hablar y el escuchar, 
el escribir incluso, eran actividades que se sustentaban en la lectura" (2013, p. 567). Para este autor, la crisis de las humanidades y de la lectura tiene que ver precisamente con la ruptura con esta idea de formación humanística vinculada con el pasado y la tradición, pues el lector se formaba en esa relación con la palabra memorable depositada en el libro ${ }^{13}$.

Sin embargo, señala, tal apropiación de la palabra se desvanece al mismo tiempo que las obras dejan de ser objetos venerables para ser objetos de uso y de consumo. Así, ese tiempo en el cual la biblioteca se presentaba como un espacio de contemplación de los libros para un lector, que a través de la palabra formaba o transformaba su sensibilidad y su carácter, va cediendo terreno con su consecuente secularización y masificación, en tanto "la desaparición de las bibliotecas es correlativa a la producción masiva de libros" (p. 587).

En este escenario de pérdida o ruptura, afirma Larrosa, la escuela intentaría mantenerse como espacio de resistencia a la completa desacralización de la biblioteca y como "un lugar donde los libros todavía

13 No obstante lo que se denomina como "el libro" es en realidad un soporte o portador de los contenidos de esa tradición y por tanto esa misma tradición puede circular en otros soportes o sustancias expresivas. En todo caso, lo que está en juego allí no es el soporte (libro impreso o libro en pantalla electrónica) en sí mismo sino las sustancias del contenido y sus formas expresivas, que en la cultura occidental son alfabéticas, y por tanto requieren la apropiación de la cultura escrita (Narváez, 2013). estarían valorados, donde todavía se mantendría una frontera entre los textos valiosos de la Cultura y los textos no valiosos del consumo ordinario... donde los libros tendrían aún algo que transmitir" (p. 588). Pero la crisis de la educación humanística va de la mano con la imposibilidad de la experiencia del libro y de la experiencia de la lectura. La cultura de masas y sus productos han surtido efecto en el lector contemporáneo. Así, rodeado de acontecimientos, desposeído de su experiencia, este "termina su jornada llena de cosas, empobrecido, vaciado, agotado, mudo. $Y$ del mismo modo, nunca se ha leído tanto como ahora y, al mismo tiempo, nunca como ahora ha sido tan difícil que el lector se convierta en experiencia" (p. 592).

En este contexto el autor se pregunta (y le pregunta al lector) si esas formas de relación con el libro que estarían apuntando entre las ruinas de la educación humanística "no implicarán para la Escuela, el abandono de su resistencia a la desaparición del pasado [...], a la cancelación de la Biblioteca [...] y al derrocamiento del Lector [...]" (2013, p. 594). Y como lectores interpelados por ese cuestionamiento respondemos que no. Que renunciar a ello es también renunciar a la posibilidad de que una cultura de élite que se mantiene ahí, entre otros, porque mantiene ese vínculo con esta tradición letrada, pueda y deba ser democratizada.

Curiosamente la renuncia a cierta nostalgia por la tradición y por 
su eje letrado la promueven quienes portan una relación con la misma. Aquellos que deben su formación justamente a este vínculo fundamental con la cultura escrita. El propio libro de Larrosa es un ejemplo valioso de ello. ¿De qué está hecho?: de una relación íntima entre un lector y muchos textos. Un lector y muchas voces que se entrecruzan en la palabra: la palabra que va abriéndose camino en un vaivén entre la lectura y la escritura, por medio del estudio. "Estudiar: leer escribiendo", anota en el prólogo, y continúa:

Con un cuaderno abierto y un lápiz en la mano. Las páginas de la lectura en el centro, las de la escritura en las márgenes. Y también: escribir leyendo. Abriendo un espacio para la escritura en medio de una mesa llena de libros (Larrosa, 2013, p. 12).

Y, ¿con quién realiza Larrosa su "experiencia de lectura", es decir, su experiencia de formación? Con clásicos de la filosofía y la literatura, desde Platón, Descartes, Rousseau, Nietzsche, Hölderlin y Heidegger hasta Proust, Handke y Goethe, entre otros.

Al igual que Gadamer (1999, p. 98) cuando propone que para educar-se es necesario el desarrollo personal de una actitud o "sensibilidad para lo que uno debe saber y para lo que uno desea saber", lo cual implica una conversación con el otro y lo otro en tanto realización plena en el lenguaje: salir de la morada para regresar transformados a ella. En ese marco, aparece la figura del estudio de los grandes pensadores, junto a la lectura de obras literarias:

Recuerdo lo que significó para mí el marcharme súbitamente de la casa paterna, es decir, el convertirme en estudiante [...] Recuerdo, por cierto, haber leído en ese año 1918 un libro de Theodor Lessing titulado Europa und Asien, porque me lo habían recomendado. Fue para mí el descubrimiento de un mundo nuevo. De ningún modo pretendo elevarlo a la categoría de genio, pero no quisiera privarme de la experiencia que tuve con la lectura de su libro. Aprendí que la crítica a la ética del rendimiento que, como optimismo del progreso, quiere dominarlo todo, era ya por ese entonces, en el año de 1918, un mensaje totalmente nuevo que me causó una profunda impresión. Fue por ese entonces que empecé a leer las novelas rusas, las escandinavas y holandesas, 
es decir, todo lo que era bueno y fácil de traducir. $Y$ así es como se forma uno. Este tipo de formación es hoy especialmente necesario en las universidades, pues los medios de masas lo dominan todo y tienen efectos ensordecedores mientras que en los planes de estudios y de preparación profesional de las universidades las especializaciones van en aumento, a despecho del nombre de "universidad" (Gadamer, 1999, p. 99).

Tal grado de especialización supone también una selección que deja por fuera "una actitud básica para abrirse camino y llegar a estar en casa en nuestro mundo" ( $p$. 99). De esta manera, para Gadamer, las experiencias decisivas, la capacidad de juicio y la formación se va restringiendo. Una vuelta a una educación liberal y no solo utilitarista estaría en la base de este pensamiento. $Y$ esta actitud básica la encontramos también en esa perspectiva de educación filosófica que nos proponía Estanislao Zuleta (1995a), como "un proceso de formación y de acceso al pensamiento y al saber en el sentido clásico en que la filosofía lo ha considerado desde la antigüedad" (p. 93). Pero no se trata aquí de sugerir un curso de filosofía, aunque también sería necesario, sino de poner el acento en la formación: "Eso significa que la enseñanza de todo lo que Ilamamos materias debe tender a darse en forma filosófica, es decir, como pensamiento, y no como conjunto de información" (p. 102).

$Y$ en el marco de estas reflexiones, ya anticipaba Zuleta (1995a) lo que serían los requerimientos "más revolucionarios" en la educación, que no consisten en formar mejor, sino en informar más rápidamente: "los sistemas audiovisuales, o los sistemas de lectura modernos de toda índole, son formas de acelerar el acceso a la información"; sin embargo, "La adquisición de una mayor cantidad de datos y su manipulación en una cantidad de tiempo no implican ninguna posibilidad de incremento de la iniciativa, de la creatividad o de la capacidad crítica" (Zuleta, 1995a, p. 100).

En contraposición a la educación como entrenamiento, como modelación de una tuerca que debe ajustar al engranaje productivo, Zuleta opone la educación platónica -y con ella la tradición socrática-, como aquella que comienza "por crear una necesidad de saber, por medio de la crítica de la opinión" (1995a, p. 96). Y a la lectura como consumo, opone la lectura como trabajo, como esfuerzo intelectual en el que el único método interpretativo es el de atreverse a pensar por sí mismo. Así también nos dice que: "solo se puede leer desde una escritura y que sólo el que escribe realmente lee" (Zuleta, 1995b).

En una defensa del cultivo de las humanidades, Nussbaum (2005) 
también observa en el método socrático un punto de apoyo para el desarrollo de esta capacidad de razonar lógicamente "de poner a prueba lo que uno lee o dice desde el punto de vista de la solidez del razonamiento, de la exactitud de los hechos y la precisión del juicio" (pp. 28-29). Las humanidades y la educación filosófica presuponen entonces, además de unos contenidos insertos en los currículos, la enseñanza y el aprendizaje de una forma de pensar mediada por la lectura.

En síntesis, Zuleta y Nussbaum, al igual que Larrosa y Gadamer, ven en la tradición humanista y racionalista y en el diálogo con los grandes pensadores a través de la lectura, una posibilidad de una educación que no es simplemente entrenamiento, sino formación de la capacidad de juicio en sentido pleno.

Desde este panorama, cabe interrogar la existencia de muchos planes de estudio de licenciatura que en la actualidad han renunciado al estudio de la Pedagogía y las humanidades en la formación de maestros, y en los cuales muchas de las prácticas de lectura se reducen a fragmentos de textos o solo a fuentes secundarias y a la escritura como el cumplimiento efectivo de una tarea. Hoy, cuando más tendríamos que construir una relación con el saber (Charlot, 2006) mediada por la lectura y el estudio a la manera de un camino posible, a la institución educativa "la vemos sucumbir ante la tentación de corear con otros la cesación de la tradición, de intentar competir con los medios de información" (Bustamante, 2013, p. 138).

Pero si estudiar es entonces lo que pasa entre el leer y el escribir, promover estas prácticas en la escuela o en la universidad es volver a aportar elementos para la configuración de un sujeto capaz de decir su palabra, capaz de pensar reflexivamente y capaz de tomar distancia crítica en torno a aquello que aparece como establecido e inamovible: la cultura misma. Quizás ningún otro pedagogo como Freire tuviese plena conciencia de ello, y por eso su lucha radical contra el analfabetismo. En una de sus "Cartas a quien pretende enseñar" (1994) nos recuerda que reducir las actividades de leer y escribir a una técnica o a un elemental ejercicio de decodificación, sin que se constituyan en prácticas vivas en el sujeto, es el mayor obstáculo para ejercer la ciudadanía, y sostiene:

Es preciso no olvidar que hay un movimiento dinámico entre pensamiento, lenguaje y realidad, del cual, si se asume bien, resulta una creciente capacidad creadora, 
de tal modo que cuanto más integralmente vivimos ese movimiento, más nos transformamos en sujetos críticos del proceso de conocer, enseñar, aprender, leer escribir, estudiar. En el fondo estudiar en su significado más profundo, abarca todas esas operaciones solidarias entre ellas (Freire, 1994, p. 6)

¿Acaso una de las tareas centrales del maestro no radica justamente en contribuir a la formación de un ciudadano, en tanto lector crítico de su realidad? Ello, sin embargo, no es posible si antes no se ha configurado el mismo maestro como lector crítico. Finalmente, valga rememorar aquella conferencia en la que Emilia Ferreiro (2002) situaba el pasado y el futuro de los verbos leer y escribir en un mundo cambiante, ese mundo que anuncia nuevas lecturas y nuevas escrituras mediatizadas. En ella, interpela a su audiencia y refiere que mientras algunos viajan por autopistas virtuales, otros no han logrado siquiera la alfabetización básica, y menos aún alcanzan la alfabetización plena, aquella que nos permite ser usuarios activos de la cultura escrita mediante el vínculo con el libro, o mejor, con lo contenido en este. Entonces imagina entre "la nostalgia conservadora" la siguiente escena:

Había una vez un niño... que estaba con un adulto... y el adulto tenía un libro... y el adulto leía. Y el niño fascinado, escuchaba cómo la lengua oral se hace lengua escrita. La fascinación del lugar preciso donde lo conocido se hace desconocido. El punto exacto para asumir el desafío de conocer y crecer (Ferreiro, 2002, p. 64).

Para que esta escena sea posible, también necesitamos imaginar de nuevo a un profesor que lee apasionadamente un libro -por ejemplo, un clásico de la literatura o de la pedagogía- a sus estudiantes, futuros maestros. Les ayuda mediante una enseñanza estimulante y aguda a buscar las claves de aquello que él mismo desea que encuentren. Lee con ellos en el aula, lee en voz alta e invita a compartir y discutir las interpretaciones creando así una comunidad de estudio y de lectores... Entonces, quizás sí podremos recrear de nuevo ese vínculo con la tradición escrita, constitutiva del oficio de maestro, de ese homo pedagogicus; en tanto nadie puede ofrecer aquello que no tiene o no le han prodigado.

\section{Referencias bibliográficas}

Álvarez, A. y León, C. (2008). ¿Para qué formar maestros? En Paradojas en la formación docente. Elementos para avanzar en su 
reflexión y planteamiento de propuestas. Bogotá: Ediciones SM.

Ávila, R. (2007). Fundamentos de pedagogía. Hacia una comprensión del saber pedagógico. Bogotá: Cooperativa Editorial Magisterio.

Carlino, P. (2005). Escribir, leer y aprender en la universidad. Una introducción a la alfabetización académica. México: Fondo de Cultura Económica.

Bernard, Ch. (2006). La relación con el saber. Elementos para una teoría. Buenos Aires: Libros del Zorzal.

Bustamante, G. (2013). Sujeto, sentido y formación. Bogotá: Universidad Pedagógica Nacional y Ediciones San Pablo.

Dubois, M. E. (1990). El factor olvidado en la formación de maestros. Lectura y Vida 4.

Ferreiro, E. (2002). Pasado y presente de los verbos leer y escribir. México: Fondo de Cultura Económica.

Freire, P. (1994). Cartas a quien pretende enseñar. Argentina: Siglo xxı Editores.

Fundación Compartir (2014). Tras la excelencia docente. Cómo mejorar la calidad de la educación para todos los colombianos. Recuperado de: http://www.fundacioncompartir.org/ pdf/Traslaexcelenciadocente18.02.2014.pdf

Gadamer, G. H. (2011). La educación es educarse. Nuevas COrrientes intelectuales. Revista de Santander 6, 90-99.

García Vera, N. O. (2011). Cultura académica y prácticas de lectura y escritura, a propósito de la formación universitaria de docentes. Pedagogía y Saberes 34, 117-139.

Larrosa, J. (2013). La experiencia de la lectura. Estudios sobre literatura y formación. México: Fondo de Cultura Económica, Colección Espacios para la Lectura.

Leme Britto, L. (2003). La cultura escrita y la formación del estudiante universitario. Lenguaje 31, 78-92.

Mockus, et al. (1997). Las fronteras de la escuela. Bogotá: Cooperativa Editorial Magisterio.

Narváez, A. (2013). Educación y comunicación. Del capitalismo informacional al capitalismo cultural. Bogotá: Universidad Pedagógica Nacional y Doctorado Interinstitucional en Educación DIE.

Pérez, A. M. y Rincón G. (2013). ¿Para qué se lee y se escribe en la universidad colombiana? Un aporte a la consolidación de la cultura académica del país. Bogotá: Colciencias y Pontificia Universidad Javeriana. 
Pérez, A. M. (2013). Estudiantes colombianos: idos décadas rajándose en comprensión lectora? Recuperado de: http://observatoriopedagogicodemedios.blogspot.com/2013/05/ estudiantes-colombianos-dosdecadas.html

Tolchinsky, L. (1990). Lo práctico, lo científico y lo literario: tres componentes en la noción de "alfabetismo". Comunicación, Lenguaje y Educación 6, 53-62.

Zuleta, E. (1995a). Educación y democracia. Un campo de combate. Cali: Fundación Estanislao Zuleta \& Corporación Tercer Milenio.

Zuleta, E. (1995b). Conferencia sobre la lectura, en Los procesos de la lectura. Jurado Valencia \& Bustamante Zamudio (comps). Bogotá: Cooperativa Editorial Magisterio. 
